\title{
Diversity of Ecto- Mycorrhizal Mushrooms in Chattisgarh
}

\author{
Kamlesh Shukla* \\ School of Studies in Biotechnology, Pt. Ravishankar Shukla University, Raipur (CG) 492010, India
}

Address for Correspondence: Kamlesh Shukla, kshukla26@gmail.com

\begin{abstract}
Keywords
Chhattisgarh; Sal

Forest:

Biodiversity;

Ectomycorrhizal

Mushroom .
\end{abstract}

\begin{abstract}
Chhattisgarh is largest tropical forest state in the country, it more diverse in ecological systems sustaining high plant endemicity (tree species) and richness of ecto mycorrhizal mushroom flora. The ectomycorrhizal mushroom is a unique group that plays a significant role in tree regeneration and ecological function of several terrestrial ecosystems. This group forms a mutualistic relationship with the roots of higher plants which gives benefits to plant such as assisting in nutrient uptake in plants by increasing root surface, altering phosphoric elements(P) from unavailable state due to bring bound by complex ions.. The purpose of present study is to relate ecto mycorrhizal mushrooms diversity in forest environment. The study was undertaken covering largest semi-ever green sal forest area in state, which harbours rich microbial wealth specially mushrooms; total 67 mushroom species belonging to 9 genera of ectomycorrhiza and 38 Agaricales were obtained from sal forests. During our systematic approach, to catalogue the indigenous mushrooms species have been recorded,viz Agaricus spp., Agrocybe spp., Amanita spp., Boletus spp., Coprinus spp., Clitocybe spp., Clavaria spp., Cortinarius spp., , Entoloma spp., Flammulina spp., Geaster spp., Inocybe spp., Lentinus spp., Lepiota spp., Lactarius spp., Pleurotus spp., Pleurotus cornucopiae, , Polyporus spp., , Russula spp., , Termitomyces spp., Tricholoma spp., Volvariella spp., Cantharellus spp. A large number of ectomycorrhizal mushrooms are found in relic mixed sal forests indicating suitable environment for the growth and occurrence of variety of mushrooms. This study was conducted with the help of Baiga tribes who are well acquainted with the periods of occurrence in varieties of habitate. Since many unexplored varieties of ectomycorrhizal mushrooms were brought to light, numerous lesser known wild mushroom flora esists in the state. The preliminary approach is to represent brief information of agarics in natural sal forest, which is more nutritious, great potential of bioactive compound, secondary metabolites, vitamins, dietary supplements as functional foods, nutraceuticals, and nutriceuticals. (C) 2016 iGlobal Research and Publishing Foundation. All rights reserved.
\end{abstract}

Conference Proceedings: International Conference on Advances in Plant and Microbial Biotechnology (PMB2017); JIIT, Noida: February 02-04, 2017

Indo Global Journal of Pharmaceutical Sciences( ISSN 22491023 ; CODEN- IGJPAI; NLM ID: 101610675) indexed and abstracted in EMBASE(Elsevier), SCIRUS(Elsevier),CABI, CAB Abstracts, Chemical Abstract Services(CAS), American Chemical Society(ACS), Index Copernicus, EBSCO, DOAJ, Google Scholar and many more. For further details, visit http://iglobaljournal.com 